\title{
Effects of Intravenous Lidocaine on Alfentanil Consumption During Procedural Sedation for Colonoscopy in Patients With Inflammatory Bowel Disease: a Randomized Controlled Trial
}

\section{Twan Aalbers ( $\nabla$ twan.aalbers@radboudumc.nl)}

Department of Anaesthesiology, Pain and Palliative Medicine, Radboud University Medical Centre, inhouse postal number 717, P.O. Box 9101, 6500HB Nijmegen, Netherlands https://orcid.org/0000-00021573-7035

Sandra A.S. van den Heuvel

Radboudumc

Ewald M. Bronkhorst

Radboudumcnenether

Aura A.J. van Esch

Gelre Ziekenhuizen

Gert Jan Scheffer

Radboudumc

Michiel Vaneker

Radboudumc

Research article

Keywords: Deep sedation, Lidocaine, Alfentanil, Colonoscopy

Posted Date: July 30th, 2020

DOI: https://doi.org/10.21203/rs.3.rs-50910/v1

License: (c) (i) This work is licensed under a Creative Commons Attribution 4.0 International License.

Read Full License 


\section{Abstract}

Background: Procedural sedation and analgesia (PSA) is used during colonoscopy to facilitate the procedure and relieve patient's discomfort. The foremost risk of PSA is respiratory depression. Lidocaine could be a promising additional analgesic in IBD patients to minimise side effects of PSA.

Our primary objective was to investigate whether i.v. lidocaine reduces the amount of alfentanil used during PSA in IBD patients. Additionally, we investigated whether lidocaine reduces cardiorespiratory incidents and the amount of propofol required during the procedure.

Methods: A randomised, double-blind, placebo controlled study was performed at the endoscopy unit of the Radboud University Medical Centre from November 2016 to December 2018. Seventy-six patients with IBD, ASA 1 or 2, between 18 and 65 years, scheduled for colonoscopy with PSA were included. Patients received lidocaine $1.5 \mathrm{mg} \mathrm{kg}^{-1}$ followed by a continuous infusion of $2 \mathrm{mg} \mathrm{kg}^{-1} \mathrm{~h}^{-1}$ (intervention group, $n=38$ ) or $0.9 \%$ saline in equivalent volumes (control group, $n=38$ ) during colonoscopy.

Results: There was a reduction in the use of alfentanil $(327 \mu \mathrm{g}(95 \% \mathrm{Cl}=-31-505, \mathrm{p}=0.082))$, and propofol (39 $\mathrm{mg}(95 \% \mathrm{Cl}=-5-83, \mathrm{p}=0.083))$ in the lidocaine group compared with the control group. Ten patients $(26 \%)$ in the control group and 8 patients in the lidocaine group $(21 \%)$ experienced a period of hypoxia $(p=0.788)$. In both groups, no periods of hypotension were noted.

Conclusion: Our investigation has shown a reduction in the use of propofol and alfentanil in patients undergoing colonoscopy with PSA. The differences were not statistically significant. Lidocaine did not reduces the incidence of cardiorespiratory events.

\section{Trial registration:}

EudraCT, 2016-002210-46, registered 19 may 2016, https://www.clinicaltrialsregister.eu/ctr-search/trial/2016-002210-46/results ISRCTN, ISRCTN47787339, retrospectively registered 6 February 2019, http://www.isrctn.com/ISRCTN47787339

\section{Introduction}

Colonoscopy is a commonly performed procedure to diagnose or follow up

inflammatory bowel disease (IBD) such as Crohn's disease and ulcerative colitis. However, colonoscopy can be an uncomfortable and painful procedure, especially in patients with IBD because of an increased visceral afferent hypersensitivity. Therefore there is an increased need of analgesics in these patients. ${ }^{(1)}$ Procedural sedation and analgesia (PSA) is used during colonoscopy to facilitate the procedure and relieve patient's discomfort. ${ }^{(2)}$ 
Propofol combined with a short-acting opioid is frequently used for PSA, due to its fast onset, improved patient satisfaction, reduced pain scores and quicker recovery. ${ }^{(3-5)}$ The foremost risk of PSA is pharmacologically induced respiratory depression. ${ }^{(6,7)}$ There is a continuous search for ways of minimising this risk.

Lidocaine has a proven analgesic effect and sparing effect on the use of opioids during abdominal surgery. ${ }^{(8,9)}$ It reduces an hyperinflammatory response and inhibits the evoked and spontaneous neuronal activity, which is activated by colorectal distension. ${ }^{(10,11)}$ One study showed that lidocaine reduces the use of propofol during colonoscopy, though did not evaluate opioid administration. ${ }^{(12)}$ Based on these studies, lidocaine could be a promising additional analgesic in IBD patients to minimise side effects on PSA.

We performed a study in IBD patients undergoing PSA for colonoscopy. We investigated if lidocaine reduces alfentanil consumption. Additionally, we investigated if lidocaine reduces the incidence of adverse cardiorespiratory events, the amount of propofol required during the procedure and postprocedural pain.

\section{Methods}

This double-blind randomised controlled trial was performed at the endoscopy unit of the Radboud University Medical Centre (Nijmegen, The Netherlands).

The study had been approved by the regional ethics committee CMO Arnhem-Nijmegen, The Netherlands (chairperson R. Dekhuijzen) on September 1, 2016 (METC nr 2016-2624), and registered at EudraCT on 19th may 2016 (2016-002210-46), All the procedures were performed in accordance with the Declaration of Helsinki. This manuscript reporting adhered to CONSORT guidelines.

\section{Randomization and blinding}

After obtaining written informed consent, patients were randomly assigned to either lidocaine or placebo treatment in a 1:1 ratio by an independent research team. The randomisation process was conducted by drawing sealed envelopes that contained the word alfentanil or saline written on a piece of paper. The first treatment that was drawn was allocated to the first subject, the second treatment drawn was allocated to the second subject and so on. Extra envelops were available in case of patients dropping out of the study before completion. The randomization details were not revealed until the end of the study. The inclusion was stopped at the moment that the 76th patient received either lidocaine or placebo. Study medication was blindly prepared and delivered in identically appearing $50 \mathrm{ml}$ syringes at the endoscopy unit.

\section{Participants}


Potential participants were assessed for eligibility during the pre-operative anaesthesia assessment. Patients with IBD, ASA 1 or 2, between 18 and 65 years, scheduled for colonoscopy with PSA were eligible for inclusion. Exclusion criteria defined as: pregnancy, emergency colonoscopy, allergies for study medication, previously diagnosed rhythm disturbances i.e. first, second or third degree AV block, Brugada syndrome, cardiomyopathy, $\mathrm{BMl}<18 \mathrm{~kg} \mathrm{~m}^{-2}, \mathrm{BMl}>35 \mathrm{~kg} \mathrm{~m}^{-2}$, obstructive sleep apnea syndrome and uncontrolled hypertension.

\section{Interventions}

Lidocaine was administered intravenously with a bolus of $1.5 \mathrm{mg} \mathrm{kg}^{-1}$ followed by a continuous infusion of $2 \mathrm{mg} \mathrm{kg}^{-1} \mathrm{~h}^{-1}$ ideal body weight. This is a commonly used dosage in abdominal surgery for analgesia. $(9,11)$ The placebo group received $0.9 \%$ saline in equivalent volumes.

All patients were monitored with non-invasive blood pressure, electrocardiography, pulse oximetry and capnography during PSA. Supplemental oxygen $\left(3 \mathrm{I} \mathrm{min}^{-1}\right)$ was administered by a nasal cannula. Procedural sedation was performed by the same health care provider in all the patients.

We performed PSA according to a standardized protocol. The Ramsey Sedation Scale score was maintained at 4 and 5 . (RSS $0-6 ; 1=$ patient is anxious, $6=$ patient is unresponsive). ${ }^{(13)}$ Patients received a bolus propofol of $1 \mathrm{mg} \mathrm{kg}^{-1}$ followed by an infusion of $4.5 \mathrm{mg} \mathrm{kg}^{-1} \mathrm{~h}^{-1}$ ideal body weight. If needed, an additional $20 \mathrm{mg}$ bolus of propofol was administered. The pain score was measured with the Wong Baker Face Scale (WBFS). ${ }^{(14,15)}$ An additional alfentanil dose of $0.25 \mathrm{mg}$ was given when a score of $\geq 4$ was observed. (WBFS $0=$ no hurts, $10=$ hurts worst) At the end of the colonoscopy total dose of propofol and alfentanil was registered.

We registered the number of incidents of hypoxia and of hypotension during PSA. Hypoxia was noted when saturation was $\leq 92 \%$ and an intervention was needed, ${ }^{(16)}$ like: vigorous tactile stimulation, airway repositioning, suctioning, increased oxygen delivery, oral or nasal airway placement, application of positive pressure or ventilation with bag mask. Hypotension was noted when mean arterial pressure $(\mathrm{MAP})<60 \mathrm{mmHg}$ and $5 \mathrm{mg}$ ephedrine was administered. ${ }^{(17)}$

After colonoscopy, patients remained at the recovery room until the Aldrete score was $\geq 9$ for at least 30 minutes (maximum total score is 10; a score of $\geq 9$ is required for discharge). ${ }^{(18)}$ Pain was assessed according to a Numeric Rating Scale (NRS 0-10; $0=$ no pain, $10=$ worst pain imaginable) when they were fully awake. ${ }^{(15)}$

Additionally, patients were asked if there was any unpleasant recall of the procedure and potential adverse effects of lidocaine were registered like tinnitus, metal taste, blurred vision or double vision.

\section{Outcomes}


The primary endpoint was the difference between alfentanil dosage in patients with and without lidocaine during the colonoscopy. Additionally we evaluated the difference in propofol dosage, the number of cardiorespiratory adverse events and postprocedural NRS between groups.

\section{Statistical analysis}

A dose of $10 \mu \mathrm{g} \mathrm{kg}^{-1}$ alfentanil is commonly used for PSA, according to this the following sample size was calculated. ${ }^{(19)}$ An alfentanil dose of $0.625 \mathrm{mg}$ in the placebo group, and $0.25 \mathrm{mg}$ in patients receiving lidocaine, with a standard deviation of $0.58 \mathrm{mg}$ was expected. This leaves us with a $n$ of 38 per group, to achieve a $80 \%$ chance for the difference of $0.375 \mathrm{mg}$ to be statistically significant with an a of 0.05 .

Descriptive statistics are presented as mean \pm SD [minimum - maximum], unless stated otherwise.

A t-test was used to compare the difference between the two groups. The frequencies of cardiorespiratory incidents and postprocedural NRS were reported and compared between groups using te Fisher Exact test. Statistical analysis was performed using IBM SPSS Statistics V25.0. $P<0.05$ was considered statistically significant.

\section{Results}

From November 2016 to December 2018, 137 patients were assessed for enrolment, and 76 were included in the data analysis, 38 for each group. Figure 1 shows the CONSORT flowchart with the excluded patients. Both groups were comparable for age, gender, weight, BMI and duration of PSA (Table 1). 
Table 1

Clinical characteristics.

\begin{tabular}{|c|c|c|}
\hline & Placebo, $n=38$ & Lidocaine, $n=38$ \\
\hline Age (years) & $38 \pm 11[21-62]$ & $37 \pm 14[19-65]$ \\
\hline \multicolumn{3}{|l|}{ Gender (n) } \\
\hline Men & 17 & 15 \\
\hline Women & 21 & 23 \\
\hline \multicolumn{3}{|l|}{ Disease (n) } \\
\hline Crohn & 31 & 31 \\
\hline Colitis ulcerosa & 7 & 7 \\
\hline $\mathrm{BMI}\left(\mathrm{kg} \mathrm{m}^{-2}\right)$ & $25.2 \pm 4.3[18.4-34.2]$ & $24.2 \pm 3.1[18.3-30.7]$ \\
\hline Duration of PSA (minutes) & $33 \pm 10$ [18-59] & $32 \pm 10[15-57]$ \\
\hline
\end{tabular}

There was a reduction in the use of alfentanil in the lidocaine group was $327 \mu \mathrm{g}$ compared with the control group. The 95\% confidence interval for this reduction is [-31-505] ( $p=0.082)$. For the use of propofol the reduction was $39 \mathrm{mg}, 95 \%$ confidence interval $=[-5-83](p=0.083)($ Table 2$)$.

No statistically significant difference in the number of hypoxia incidents between groups was found $(\mathrm{p}=$ 0.788). Ten patients (26\%) in the control group and eight patients in the lidocaine group (21\%) experienced a period of hypoxia. No periods of hypotension were noted.

Postprocedural NRS scores were similar in both groups. Thirty-five patients in the control group and 33 patients in the intervention group reported no pain postcolonoscopy. Patients who participated in the study had no side effects on the lidocaine. 
Table 2

Outcome Measures

\begin{tabular}{|llll|}
\hline & Placebo & Lidocaine & P value \\
\hline Alfentanil $(\mu \mathrm{g})$ & $868 \pm 647[0-2500]$ & $632 \pm 519[0-1750]$ & 0.082 \\
\hline Propofol $(\mathrm{mg})$ & $387 \pm 106[222-665]$ & $349 \pm 85[181-556]$ & 0.095 \\
\hline Hypoxia $(\mathrm{n})$ & $10(26 \%)$ & $8(21 \%)$ & 0.788 \\
\hline Hypotension $(\mathrm{n})$ & 0 & 0 & 1.000 \\
\hline Postcolonoscopy pain (NRS) & $0[0-8]$ & $0[0-8]$ & 1.000 \\
\hline Data are presented as number $(n)$, mean \pm SD [range], or median [range]. \\
\hline
\end{tabular}

\section{Discussion}

This randomized controlled trial in IBD patients undergoing PSA for a colonoscopy has shown a reduction in the use of alfentanil and propofol. The differences were not statistically significant. No difference in hypoxia, hypotension and postprocedural pain scores was found.

Lidocaine reduces anaesthetic requirements in abdominal procedures. One study investigated the effect of lidocaine during colonoscopy. Lidocaine reduced propofol requirements, and improved postcolonoscopy pain and fatigue. ${ }^{(12)}$ The effect of lidocaine on opioid consumption during PSA has not been investigated yet. In abdominal surgery lidocaine reduces perioperative opioid requirements. ${ }^{(8,11)}$

We found a large interpatient variability in anaesthetic requirement, leading to only a tendency for reduced alfentanil and propofol requirements. This variability may be explained by the variety execution of the procedure and pain sensitivity between patients. Further research is needed in patients with a high pain sensitivity or who previously needed a high dose of alfentanil during a colonoscopy. Although we studied IBD patients, only few patients experienced postprocedural pain and pain-scores were low. In our study $\mathrm{CO}_{2}$ insufflation was used during colonoscopy. $\mathrm{CO}_{2}$ insufflation induces less postprocedural pain compared with nitrogen due to more rapid absorption. ${ }^{(20)}$

The incidence of cardiorespiratory events were similar in both groups. Hypoxia secondary to respiratory depression and airway obstruction is the most frequent complication of PSA during colonoscopy. ${ }^{(6,16)}$ In our study $24 \%$ of the patients have undergone a period of hypoxia, which is comparable with most other studies $^{(21)}$.

None of the patients in our study experienced a period of hypotension, which is a relative rare adverse event during PSA, ${ }^{(6,16)}$ especially in a study population without cardiovascular comorbidity. However, the reporting of sedation-related complications has been subject to substantial variability due to differences 
in PSA depth and criteria for hypoxia or hypotension. A recent study suggested advice for evaluating sedation-related complications. ${ }^{(6)}$

Our study has some limitations. Procedures were performed by several endoscopist and we did not include technically difficulty as a variable since this can be related to uncomfortable procedure. ${ }^{(22)}$ This could have influenced our conclusions regarding the effect of lidocaine on alfentanil consumption. PSA was performed by the same physician assistant so there is no risk of seditionist dependent bias.

\section{Conclusion}

There was a trend for reduced alfentanil and propofol consumption in patients receiving lidocaine during colonoscopy under PSA in IBD patients. Lidocaine did not reduce the incidence of cardiorespiratory events or postprocedural pain. Based on these results standard administration of lidocaine may be helpful in patients with high need for alfentanil during colonoscopy, further investigation is needed.

\section{Declarations}

\section{Ethics approval and consent to participate}

The study had been approved by the regional ethics committee CMO Arnhem-Nijmegen, The Netherlands (chairperson R. Dekhuijzen) on September 1, 2016 (METC nr 2016-2624).

\section{Consent for publication}

Not applicable

\section{Availability of data}

The datasets used and/or analysed during the current study are available from the corresponding author on reasonable request

\section{Competing interests}

The authors declare that they have no competing interests

\section{Funding}

Departmental funding only

\section{Authors' contributions}

All authors have read and approved the manuscript. All authors contributed to the interpretation of results and revision of manuscript, as follows: T.A., S.H., M.V. G.J.S, E.B. and A.E.: study concept and design and 
redaction of the manuscript; T.A.: patient recruitment, measurements and data collection; E.B.: randomization and statistical analysis

\section{Acknowledgements}

Not applicable

\section{References}

1. Denters MJ, Schreuder M, Depla AC, Mallant-Hent RC, van Kouwen MC, Deutekom M, et al. Patients' perception of colonoscopy: patients with inflammatory bowel disease and irritable bowel syndrome experience the largest burden. Eur J Gastroenterol Hepatol. 2013;25(8):964-72.

2. Lu Y, Hao LX, Chen L, Jin Z, Gong B. Systematic review and meta-analysis of patient-controlled sedation versus intravenous sedation for colonoscopy. Int J Clin Exp Med. 2015;8(11):19793-803.

3. Michel Foehn ER. Adult and pediatric anesthesia/sedation for gastrointestinal procedures outside of the operating room. Curr Opin Anaesthesiol. 2015;28(4):469-77.

4. Schroeder C, Kaoutzanis C, Tocco-Bradley R, Obear J, Welch KB, Winter S, et al. Patients Prefer Propofol to Midazolam Plus Fentanyl for Sedation for Colonoscopy: Results of a Single-Center Randomized Equivalence Trial. Dis Colon Rectum. 2016;59(1):62-9.

5. Wang $D$, Chen $C$, Chen J, Xu Y, Wang L, Zhu Z, et al. The use of propofol as a sedative agent in gastrointestinal endoscopy: a meta-analysis. PLoS One. 2013;8(1):e53311.

6. Roback MG, Green SM, Andolfatto G, Leroy PL, Mason KP. Tracking and Reporting Outcomes Of Procedural Sedation (TROOPS): Standardized Quality Improvement and Research Tools from the International Committee for the Advancement of Procedural Sedation. $\mathrm{Br} \mathrm{J}$ Anaesth. 2018;120(1):164-72.

7. Conway A, Douglas C, Sutherland J. Capnography monitoring during procedural sedation and analgesia: a systematic review protocol. Syst Rev. 2015;4:92.

8. McCarthy GC, Megalla SA, Habib AS. Impact of intravenous lidocaine infusion on postoperative analgesia and recovery from surgery: a systematic review of randomized controlled trials. Drugs. 2010;70(9):1149-63.

9. Kranke P, Jokinen J, Pace NL, Schnabel A, Hollmann MW, Hahnenkamp K, et al. Continuous intravenous perioperative lidocaine infusion for postoperative pain and recovery. Cochrane Database Syst Rev. 2015(7):CD009642.

10. Ness TJ. Intravenous lidocaine inhibits visceral nociceptive reflexes and spinal neurons in the rat. Anesthesiology. 2000;92(6):1685-91.

11. van der Wal SE, van den Heuvel SA, Radema SA, van Berkum BF, Vaneker M, Steegers MA, et al. The in vitro mechanisms and in vivo efficacy of intravenous lidocaine on the neuroinflammatory response in acute and chronic pain. Eur J Pain. 2016;20(5):655-74. 
12. Forster $C$, Vanhaudenhuyse A, Gast P, Louis E, Hick G, Brichant JF, et al. Intravenous infusion of lidocaine significantly reduces propofol dose for colonoscopy: a randomised placebo-controlled study. Br J Anaesth. 2018;121(5):1059-64.

13. Avci S, Bayram B, Inanc G, Goren NZ, Oniz A, Ozgoren M, et al. Evaluation of the compliance between EEG monitoring (Bispectral IndexTM) and Ramsey Sedation Scale to measure the depth of sedation in the patients who underwent procedural sedation and analgesia in the emergency department. Ulus Travma Acil Cerrahi Derg. 2019;25(5):447-52.

14. Garra G, Singer AJ, Taira BR, Chohan J, Cardoz H, Chisena E, et al. Validation of the Wong-Baker FACES Pain Rating Scale in pediatric emergency department patients. Acad Emerg Med. 2010;17(1):50-4.

15. Hjermstad MJ, Fayers PM, Haugen DF, Caraceni A, Hanks GW, Loge JH, et al. Studies comparing Numerical Rating Scales, Verbal Rating Scales, and Visual Analogue Scales for assessment of pain intensity in adults: a systematic literature review. J Pain Symptom Manage. 2011;41(6):1073-93.

16. Bhatt M, Kennedy RM, Osmond MH, Krauss B, McAllister JD, Ansermino JM, et al. Consensus-based recommendations for standardizing terminology and reporting adverse events for emergency department procedural sedation and analgesia in children. Ann Emerg Med. 2009;53(4):426-35. e4.

17. Walsh M, Devereaux PJ, Garg AX, Kurz A, Turan A, Rodseth RN, et al. Relationship between intraoperative mean arterial pressure and clinical outcomes after noncardiac surgery: toward an empirical definition of hypotension. Anesthesiology. 2013;119(3):507-15.

18. Aldrete JA. The post-anesthesia recovery score revisited. J Clin Anesth. 1995;7(1):89-91.

19. Turk HS, Aydogmus M, Unsal O, Koksal HM, Acik ME, Oba S. Sedation-analgesia in elective colonoscopy: propofol-fentanyl versus propofol-alfentanil. Braz J Anesthesiol. 2013;63(4):352-7.

20. Kim HG. Painless Colonoscopy: Available Techniques and Instruments. Clin Endosc. 2016;49(5):444-8.

21. Waugh JB, Epps CA, Khodneva YA. Capnography enhances surveillance of respiratory events during procedural sedation: a meta-analysis. J Clin Anesth. 2011;23(3):189-96.

22. Park DI, Kim HJ, Park JH, Cho YK, Sohn Cl, Jeon WK, et al. Factors affecting abdominal pain during colonoscopy. Eur J Gastroenterol Hepatol. 2007;19(8):695-9.

\section{Supplementary Files}

This is a list of supplementary files associated with this preprint. Click to download.

- CONSORT2010Checklistbmc.doc 